\title{
EXTENSÃO X AFASTAMENTO SOCIAL: O CASO DE ATELIÊ DE PROJETOS INTEGRADOS III ${ }^{1}$
}

\author{
EXTENSION X SOCIAL DISTANCING: \\ THE CASE OF THE INTEGRATED PROJECTS STUDIO III
}

\author{
Anelis Rolão Flores ${ }^{2}$, Clarissa de Oliveira Pereira ${ }^{3}$ e Francisco Queruz ${ }^{4}$
}

\section{RESUMO}

Este artigo tem como objetivo relatar o impacto na disciplina extensionista de Ateliê de Projetos Integrados III, intervenções em preexistências, do isolamento social imposto pela COVID-19. O Ateliê III realiza levantamentos de edificações históricas para a elaboração de projetos, nas escalas arquitetônica, urbanística e paisagística. Na construção destes projetos, os acadêmicos geram material de auxílio para o poder público, assim como permitem a formação da responsabilidade social e a difusão na comunidade. A disciplina que possui seu foco na educação patrimonial e no impacto positivo da preservação na sociedade, assumiu, em 2019, o caráter extensionista de forma mais sistemática ao ampliar sua atuação, inserindo-se no Projeto de Extensão Institucional Centro Histórico de Santa Maria. A partir dessa conexão, ações foram desenvolvidas culminando no "Giro Histórico", caminhada patrimonial de divulgação dos resultados à comunidade. Porém, em 2020, com a pandemia, o desenvolvimento de projetos precisou equilibrar atividades síncronas e assíncronas, gerando um novo modo de interação com a sociedade. O material, levantamento e análise, explorou os recursos virtuais e resultou em uma conferência como meio de divulgação e, principalmente, de discussão sobre o patrimônio ferroviário. Afinal, a atuação da disciplina visa garantir o reconhecimento e a relevância das edificações em destaque, para a história da cidade e região, e precisou considerar novos rumos. Revelando que o patrimônio, embora impactado de forma negativa pelo desenvolvimento econômico em tempos de economia em expansão, também desaparece em situações de grande abandono como o momento atual que estamos vivendo.

Palavras-chave: Patrimônio Ferroviário, Ensino e extensão, Centro Histórico de Santa Maria, Educação patrimonial.

\section{ABSTRACT}

This article aims at reporting the impact in the extensionist subject of Integrated Projects Studio III, interventions in pre-existences, due to the social isolation imposed by COVID-19. Studio III carries out surveys of historic buildings for the elaboration of projects, in the architectural, urban and landscape scales. In the construction of these projects, the academics generate aid material for the public authorities, as well as allow the formation of social responsibility and dissemination in the community. The subject that is focused on heritage education and on the positive impact of preservation on society, assumed, in 2019, the extensionist character in a more systematic way by expanding its action, inserting itself in the Institutional Extension Project Historic Center of Santa Maria. From this connection, actions were developed culminating in the "Giro Histórico", a heritage walk to disseminate the results to the community. However, in 2020, with the pandemic, the development of projects needed to balance synchronous and asynchronous activities, generating a new mode of interaction

1 Disciplina extensionista do curso de Arquitetura e Urbanismo da Universidade Franciscana / Santa Maria/ RS.

2 Arquiteta e Urbanista. Doutora e Mestre em Arquitetura. E-mail: anelis@ufn.edu.br

3 Arquiteta e Urbanista. Doutora em Arquitetura. E-mail: clarissapereira@ufn.edu.br

4 Arquiteto e Urbanista. Mestre em Engenharia Civil. E-mail: francisco@ufn.edu.br 
with society. The material, survey and analysis, explored virtual resources and resulted in a conference as a means of dissemination and, mainly, discussion about the railway heritage. After all, the action of the subject aims at ensuring the recognition and relevance of the buildings in focus, for the history of the city and region, and needed to consider new directions. Revealing that the heritage, although negatively impacted by economic development in times of booming economy, also disappears in situations of great abandonment as the current moment we are living in.

Key-words: Railway Heritage; Heritage Education; Historic Center of Santa Maria; Teaching and Extension.

\section{INTRODUÇÃO}

O Ateliê Itinerante configura-se como um subprojeto de ensino-extensão dentro do Projeto Integrador de Extensão denominado Identidade e Inovação Social da Universidade Franciscana, que abrange diversas disciplinas, e busca auxiliar na formação profissional aliada a responsabilidade social dos acadêmicos do curso de Arquitetura e Urbanismo. O Ateliê de Projetos Integrados III, intervenções em preexistência, faz parte deste ateliê âncora e se organiza de forma a interagir com a comunidade nas questões referentes à temática da preservação do patrimônio e sua respectiva educação patrimonial.

A disciplina que desde o momento da sua proposição, em 2006, teve como foco a educação patrimonial e seu impacto na sociedade, adquiriu, em 2019, o caráter extensionista de forma mais sistemática por meio da curricularização da extensão ${ }^{5}$. Na ocasião, a atuação extensionista foi ampliada para contemplar o Projeto de Extensão Institucional Centro Histórico de Santa Maria, com o estudo da Estação Férrea de Santa Maria e suas adjacências. A partir dele, uma série de ações foram propostas, resultando no denominado "Giro Histórico", caminhada guiada pelo centro da cidade até a estação ferroviária para apresentação dos trabalhos. Porém no ano de 2020, com o isolamento social imposto pela pandemia da COVID-19, a disciplina de Ateliê III precisou se reinventar e adequar o seu conteúdo extensionista à nova realidade acadêmica, de modo a equilibrar atividades, síncronas e assíncronas, às novas maneiras de impactar a sociedade e promover conhecimento patrimonial. O produto foi a conferência virtual, live, intitulada "Diálogos sobre Patrimônio Ferroviário", que encerrou a disciplina em 15 de janeiro de 2021.

As atividades de extensão, anteriormente experimentadas, utilizaram de levantamentos cadastrais e ações presenciais, entretanto devido ao isolamento social os levantamentos foram realizados de forma mais analítica, com materiais já existentes, e a presencialidade nas ações tiveram que ser substituídas por outros meios de comunicação. Estas inovações permitiram, também, alcançar a sociedade por meio de diálogos que extrapolaram a esfera local e difundiram conceitos mais amplos de preservação.

\footnotetext{
5 Embora a extensão universitária estivesse prevista desde o Decreto ${ }^{\circ} 19.851$, de 11/4/1931, que estabeleceu as bases do sistema universitário brasileiro, é a partir da Resolução do MEC - CNE/CES 7/2018 que ela se torna obrigatória nos currículos dos cursos de graduação por meio das disciplinas extensionistas. Tal exigência trouxe novos questionamentos e novas possibilidades ao ensino superior, fomentando a discussão sobre como essa prática seria inserida teórica e metodologicamente nos cursos de graduação.
} 
Percebe-se, portanto, que a conjugação entre academia e a comunidade precisa se basear em um equilíbrio de aprendizado, em trocas de experiências, a fim de provocar a transformação das ideias e a superação dos preconceitos recíprocos, pois são mais que projetos, são experiências que buscam viabilizar a interação e promover a educação patrimonial.

\section{A EXTENSÃO E AS AÇÕES PRESERVACIONISTAS}

O curso de Arquitetura e Urbanismo da Universidade Franciscana, desde sua primeira conformação, manteve em destaque a responsabilidade social na sua estrutura, com disciplinas projetivas, teóricas e teórico-práticas que já possuíam em suas ementas a aproximação com as comunidades, assim como o estudo de ações com impacto na cidade de Santa Maria e região. Portanto, no momento da implantação da curricularização da extensão, o Ateliê III foi um dos primeiros identificado com aplicação e conteúdo extensionista, pois já possuía uma caminhada de treze edições com projetos conectados com as comunidades e que permitiam a sensibilização acadêmica, características fundamentais para o desenvolvimento da tão almejada educação patrimonial na extensão.

A estrutura de elaboração de projetos com a temática do Patrimônio Histórico no Ateliê III foi criada a partir das ideias da memória e das suas relações com a história. Neste sentido, a seleção da memória e a sua preservação ultrapassam o limite do edificado e se aproximam das questões referentes à memória cultural, aos espaços de recordação que possuem um poder de vínculo com a comunidade. Ao admitirmos a ligação, muitas vezes indissociável, entre memória e espaço precisamos refletir, também, sobre o esquecimento e o poder que tem o arquiteto sobre ele, sobre a edificação que será objeto do projeto. Portanto, aproximamos as questões referentes à preservação do patrimônio edificado ao pensamento de Assmann:

Por um lado, espaços de recordação surgem por meio de uma iluminação parcial do passado, do modo como um indivíduo ou um grupo precisam dele para a construção de sentido, para a fundação de sua identidade, para a orientação de sua vida, para a motivação de suas ações. (...) O que se seleciona para a recordação sempre está delineado por contornos do esquecimento. O recordar que enfoca e concentra implica esquecimento (ASSMANN, 2011, p. 437).

Além da memória física da edificação devemos também considerar a memória oral do grande grupo, no caso do Ateliê os ferroviários e usuários desta modalidade. A história de vida busca reconstituir vivências e transmitir experiência, e o pesquisador deve então desvendar suas conexões e contribuições para experiência do grupo e para o resgate dos dados pertinentes. O pesquisador, ainda, deve transcender o relato simplificado para a narração de uma experiência de vida buscando potencializar o encontro com os personagens desta história. O objetivo deverá sempre focar no narrador, pois “A memória oral pode captar a experiência efetiva dos narradores, mas também recolhe destes as tradições e mitos, narrativas de ficção, crenças existentes no grupo, assim como relatos que contadores (...) inventam num dado momento" (QUEIROZ, 1987, p. 278). 
Outra questão importante é a responsabilidade social e cultural na formação do profissional arquiteto, pois ao intervir em áreas urbanas, conjuntos arquitetônicos e edificações de interesse de preservação, o profissional deverá considerar que estes são testemunhos únicos e que sua ação deve ser precisa e criteriosa, fugindo de premissas sem fundamentação que podem causar danos irreversíveis. Deverá considerar também, o impacto no patrimônio dos acréscimos e das subtrações propostas no seu projeto, assim como o risco de não manter a reversibilidade, característica tão requerida nas intervenções atuais, pois permite o retorno ao original. Segundo Kühl:

É necessário voltar a entender por que e para quem se preserva - e, por conseguinte, também o que se preserva-, qual a vinculação da preservação com a cultura, retomando os princípios fundamentais que regem o campo, para alcançar uma necessária coerência conceitual que guie o modo de preservar. Dessa forma, pode-se, de maneira consciente, retomar o caminho e consolidar vias abrangentes para a preservação, também como meio de refrear a ignorância e o consumismo que ameaçam, mais do que nunca, o tratamento dos bens culturais (KÜHL, 2008, p. 276)

Dentro deste contexto, convém destacar que a disciplina tem como objetivo o desenvolvimento de habilidades teóricas e projetuais que permitam a proteção, recuperação e valorização da memória e do patrimônio histórico. Neste sentido, a educação patrimonial busca sensibilizar os acadêmicos e comunidade para questões referentes às ações de preservação, individuais e coletivas, que contribuam na construção de conhecimento, pertencimento, e consequente melhoria da qualidade de vida.

As três escalas dos projetos, arquitetônico, paisagístico e urbanístico, demonstram a importância do trabalho de configuração da paisagem urbana que é formada pelas sucessivas transformações históricas, sejam de natureza social, urbanística ou até das edificações. Para tanto, ao identificarmos uma edificação patrimonial para o desenvolvimento do projeto arquitetônico, também consideramos as construções que conformam o seu entorno, suas camadas históricas, seus períodos e seus estilos arquitetônicos, assim como possíveis locais para a implantação de uma praça conectando a edificação a um contexto urbano e transformando-a em uma edificação âncora. Os valores utilizados para a escolha das edificações, consideram o caminho apontado por Kühl:

Ao identificar um bem como de interesse cultural, devem-se levar em consideração os valores documentais, formais, memoriais e simbólicos de interesse para a coletividade como um todo - e não simples aspirações imediatistas ou setoriais - para transmití-los para as gerações futuras, através de intervenções pautadas nos aspectos documentais, formais e materiais, respeitando-os de maneira mais ampla possível (KÜHL, 2008, p. 269).

Ressaltamos que esses projetos sempre foram além dos limites acadêmicos da disciplina envolvendo comunidades e o governo, proporcionando o resgate não só das edificações como das memórias locais, produzindo material gráfico, com base nos levantamentos e análises realizados pelos alunos. Os acadêmicos são orientados e desenvolvem habilidades para executar os levantamentos, cadastral e fotográfico, utilizando materiais e ferramentas adequadas, por meio de um roteiro estabelecido em sala de aula, pois 
assim conseguem agilizar e qualificar a técnica. Já as análises ampliam este material, possibilitando a elaboração de outros itens, como diagnósticos, entrevistas, mapas, collages, vídeos, etc. Em ambos os casos o material, a ser complementado, poderá partir de uma base existente, tanto de desenhos técnicos como de dados existentes em cadastros eletrônicos de órgãos públicos, federais, estaduais e municipais.

A partir da compilação e cessão dos levantamentos cadastrais foi possível fomentar trabalhos institucionais, em prefeituras e Conselhos do Patrimônio, que esbarravam na falta de mão de obra especializada.

O produto extensionista gerado permite ir além do material gráfico e consegue realizar o registro da memória oral por meio de envolvimento com a comunidade, muitas vezes resgatando informações existentes e ainda registrando novos fatos e informações inexistentes na bibliografia. Também, existe um retorno não só para a comunidade como para a sociedade como um todo, no momento da publicação e apresentação, por meio de palestras, reuniões e vídeos, do material elaborado nos semestres.

A primeira edição da disciplina de Ateliê III ocorreu em 2006 e na ocasião a edificação escolhida foi o Açougue, Fábrica de Sabão e Torrefação de Café, imóvel que pertenceu à Viação Férrea e consistia em proporcionar apoio à comunidade ferroviária. Porém foi em 2012 que as estações de trem passaram a protagonizar os estudos do Ateliê, e desde então onze estações de diferentes tipologias e graus de importância foram estudadas e seu material analisado, compilado, para assim propor novos usos em projetos nas três escalas. Foram elas: Estação Colônia, Bairro Camobi em Santa Maria (2012), Estação Val de Serra (2013), Estação Pinhal, em Itaara (2013), Estação Arroio do Só (2014), Estação São Pedro (2015), Estação Dilermando de Aguiar (2016), Estação Estiva, em Restinga Seca (2017), Estação Jacuí, em Restinga Seca (2017), Estação de Mata (2018), Estação de Santa Maria (2019) e Estação e Armazéns do Km2, em Santa Maria (2020).

A escolha das estações partiu do reconhecimento que no momento da sua instalação a dinâmica do seu entorno foi alterada gerando uma articulação de desenvolvimento local com verdadeiro impacto urbano e social. Assim como no momento da desarticulação do sistema ferroviário, na década de 1990, que acarretou não apenas na perda do protagonismo como mudanças estruturais em localidades e regiões específicas das cidades estudadas. Na maioria dos casos estudados podemos observar a degradação não apenas das edificações, como ainda a desestruturação do seu entorno, com invasões e ocupações irregulares, contribuindo para a formação de uma situação complexa e que necessita de estratégias projetuais específicas.

No ano de 2019, a disciplina passou a incluir o caráter extensionista de forma sistemática e menos intuitiva, pois na primeira avaliação da matriz curricular destacou-se pela extensão até o momento desenvolvida pelos alunos. Em 2020, com o isolamento social, a disciplina se reinventou e adequou o seu conteúdo extensionista à nova realidade acadêmica, de modo a equilibrar atividades, síncronas e assíncronas, às novas maneiras de impactar a sociedade e promover conhecimento patrimonial. 
Portanto, as ações extensionistas desenvolvidas na disciplina conseguem atingir a sociedade como um todo, além de promover o resgate da memória e aproximação com a comunidade remanescente do período ferroviário, com grupos coletivos e entidades de defesa do patrimônio e com escolas. A seguir serão descritas as duas últimas edições que tiveram como temática o patrimônio ferroviário de Santa Maria.

\section{EDIÇÃO 2019: PERCORRENDO O CENTRO HISTÓRICO DE SANTA MARIA}

A partir do ano de 2019, foi iniciado um projeto de extensão pela UFN chamado Centro Histórico de Santa Maria, reunindo diversos cursos de áreas afins ${ }^{6}$, além de outras instituições de ensino, do poder municipal e da sociedade civil ${ }^{7}$. Os objetivos deste projeto eram relacionados com a criação de estudos aprofundados e proposições de ações para a área central da cidade, que acabara de ser desprotegida pela retirada da chamada Zona 2 do Plano Diretor de Desenvolvimento Urbano e Ambiental, PDDUA, de $2009^{8}$. Também eram relacionados a necessidade de criação de articulações entre esses entes, que desenvolviam ações isoladas e, por vezes, sobrepostas.

A demanda identificada por meio dessas articulações foi a principal razão para que, na disciplina de Ateliê III, o sítio de estudo em 2019 voltasse a ser Santa Maria. A efervescência de discussões, fontes e atores permitiu que os olhos se voltassem ao principal símbolo do desenvolvimento da cidade durante a primeira metade do século XX: a Estação Férrea Central.

A Gare de Santa Maria ${ }^{9}$ é a principal protagonista de uma fase de desenvolvimento que se iniciou em 1885 , com a chegada dos trilhos na cidade $^{10}$, e que iniciou o chamado ciclo ferroviário (Figura 01). A principal linha de ferro que conectava o desenvolvido Leste, Porto Alegre, ao longínquo Oeste, Uruguaiana, passava por Santa Maria, tornando-a um importante ponto de conexão no interior do estado. Iniciava nessa também a linha que conectaria os estados do Rio Grande do Sul e São Paulo, chegando a Itararé. Em cerca de 25 anos, o povoado alterou assim a sua hierarquia e passou a pertencer à principal rota estadual de transporte de cargas e pessoas, e justamente em seu entroncamento. Não bastasse a importância ditada por essa confluência de vias, Santa Maria também passou a receber a sede da nova arrendatária das ferrovias gaúchas, a

6 Arquitetura e Urbanismo, Design, Direito, Jornalismo, História e Publicidade e Propaganda.

7 Universidade Federal de Santa Maria (UFSM), Agência de Desenvolvimento de Santa Maria (ADESM), Coletivo Memória Ativa, entre outros.

8 O PDDUA de Santa Maria, datado de 2006, e depois atualizado em 2009, havia criado uma zona de proteção no perímetro chamado de Centro Histórico (Zona 2). Este zoneamento previa, para a área, que edificações deveriam ser analisadas pelo então Escritório da Cidade, autarquia responsável, junto ao Conselho Municipal de Patrimônio Histórico e Cultural (COMPHIC), de avaliar o valor dos bens já construídos, mesmo que sem proteção específica prévia.

9 Terminologia, oriunda do francês, para estação passou a ser usada a partir da década de 1990, em Santa Maria, possivelmente como reflexo dos projetos de revitalização em estações daquele país, na década anterior.

10 No período de chegada da linha de Porto Alegre, foi construída uma estação no bairro Itararé, que foi posteriormente demolida, próxima a 1900, para dar lugar à existente até os dias de hoje. 
Compagnie Auxiliaire des Chemins de Fer au Brésil, empresa de capital belga que trouxe funcionários e criou equipamentos para gerir a malha a partir daqui. A estação Santa Maria passou a ser o quilômetro zero das ferrovias do estado e durante toda a primeira metade do século XX, seus atores sustentaram uma sociedade ferroviária local que criou a mais variada sorte de equipamentos para seu uso e de seus funcionários, além de fomentar a criação de serviços diversos nos arredores da estação para os usuários desse tipo de transporte (DIAS, 1986; MELLO, 2010).

Figura 01 - Estação férrea em 1914, promovendo o desenvolvimento econômico e social de Santa Maria na época. Podemos observar que os pavilhões laterais ainda não estavam construídos.

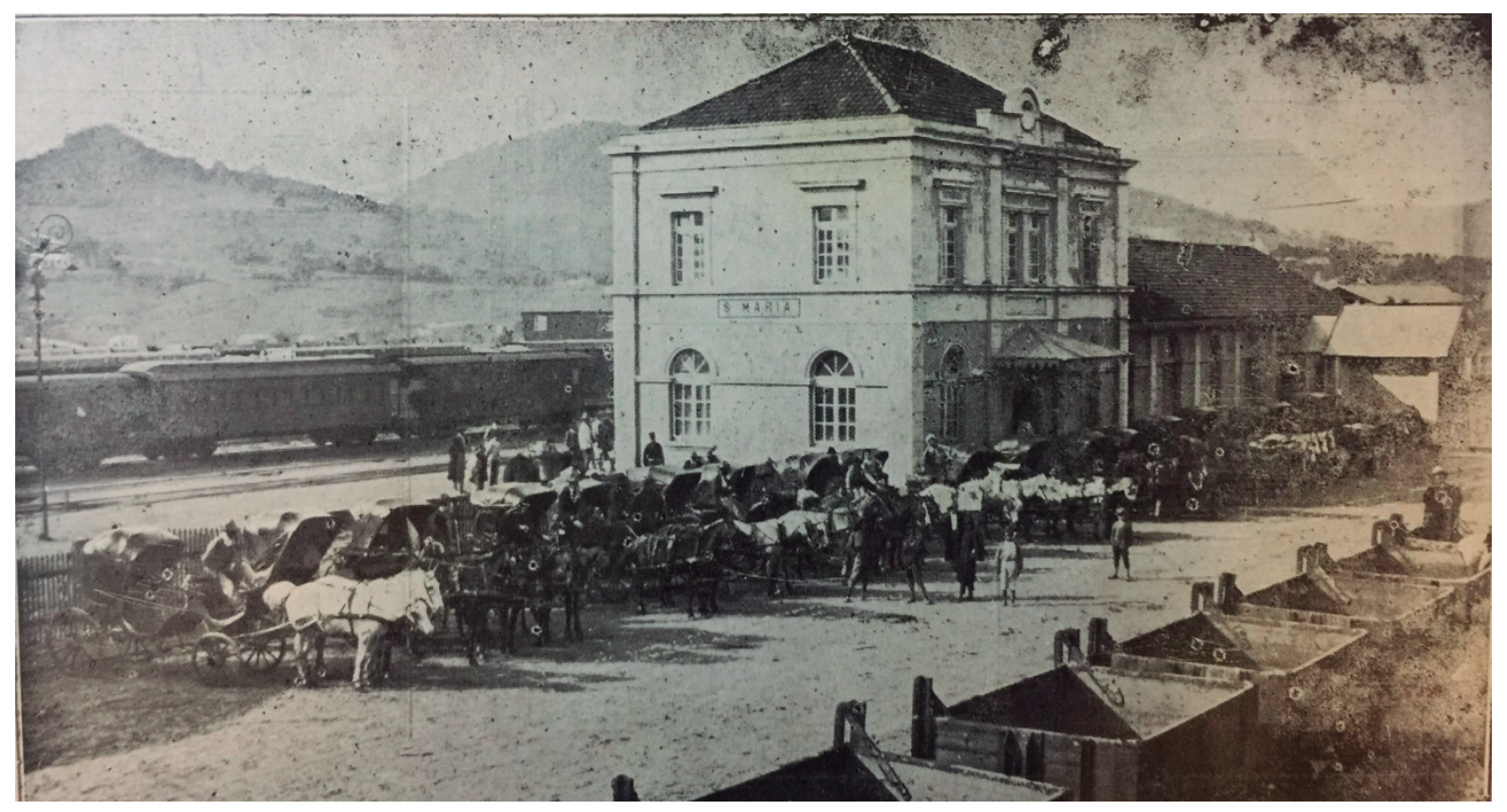

Fonte: Beltrão, 1958.

Contudo, o valor das ferrovias para a sociedade local e brasileira começou a reduzir a partir da década de 1950, com novas políticas e o incremento do transporte rodoviário. As décadas de 1980 e 1990 foram definitivas ao transporte ferroviário estatal: extinção de transporte de passageiros e posterior concessão da malha. Em março de 1997, o governo federal colocou fim as atividades da estação de Santa Maria. Por outro lado, foi permitido ao poder municipal solicitar a concessão de uso do edifício da antiga estação, já em desuso na época. Nos anos seguintes ainda ocorreram os tombamentos municipal e estadual da estação, assim como uma intervenção por parte do município para habilitar o bem para seus novos usos, que, contudo, não foram suficientes para manter a edificação em funcionamento (Figura 02). 
Figura 02 - Vista parcial da estação de Santa Maria, em 2019, em desuso e parcialmente depredada.

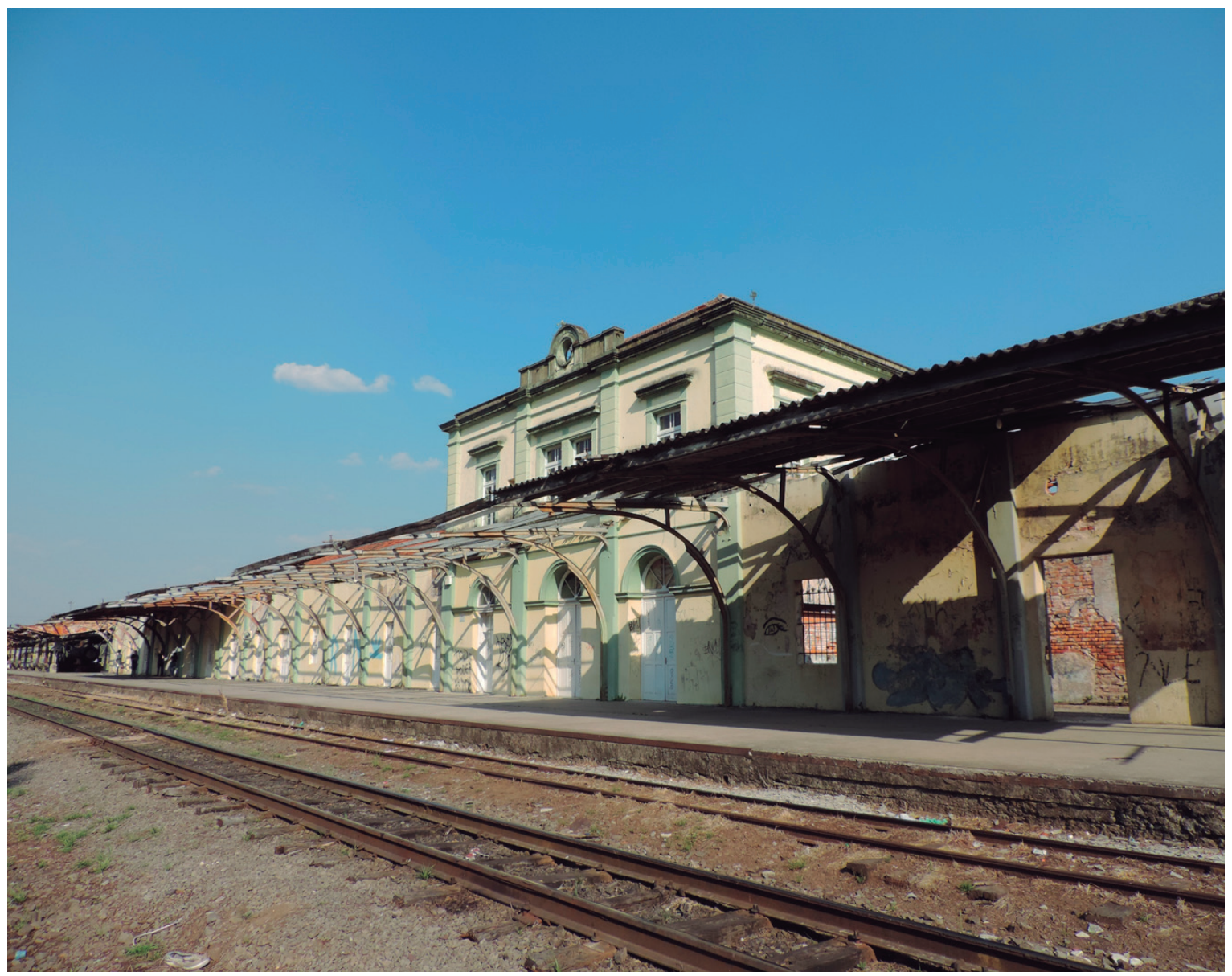

Fonte: Acervo dos alunos de Ateliê de Projetos integrados III, 2019.

Essa edificação, de relevância inquestionável à história e ao desenvolvimento do município, foi o foco dos trabalhos desenvolvidos, no ano de 2019, na disciplina de Ateliê de Projetos Integrados III, junto com o tecido urbano que conectava a mesma até o núcleo de formação inicial de Santa Maria, na praça Saldanha Marinho. As atividades extensionistas que foram desenvolvidas ao longo do semestre podem ser divididas em dois grupos: de levantamento e de produto.

As atividades de levantamento são relacionadas a atualização do levantamento físico cadastral que o Instituto de Planejamento de Santa Maria, IPLAN, autarquia do poder executivo municipal, possuía no momento. Nesse caso, foram estabelecidas relações para obtenção do material, para então o grupo de alunos compreender e realizar as alterações percebidas, em especial pela depreciação do bem ao longo dos anos. Foi possível que os alunos tivessem acesso aos técnicos do IPLAN, acessassem também as instalações da estação férrea, para então realizar os ajustes necessários para desenvolver a etapa acadêmica de projeto. Na escala urbana, os alunos desenvolveram, nesse momento, um diagnóstico urbano da realidade consolidada desse entorno, atentando para a vitalidade e para os exemplares arquitetônicos relevantes e ainda remanescentes na área, que possuíam relação com o contexto ferroviário. 
Os produtos alcançados ao final da disciplina compõem o outro grupo de atividades listadas. Foram organizadas em torno de uma ação extensionista chamada "Giro Histórico", que teve como objetivo principal mostrar os resultados em uma tarde aberta à comunidade, de forma geral (Figuras 03 e 04). Para tanto, foi organizado um passeio, que iniciou sua caminhada na praça Saldanha Marinho e, seguindo o Projeto Interpretativo ${ }^{11}$ proposto pelo grupo, foi finalizado junto à Estação Férrea e ao centro comercial localizado na edificação da antiga cooperativa dos ferroviários. Além de percorrer a Avenida Rio Branco e elencar edificações de valor para a história municipal, ao fim do percurso foi realizada uma seção de audiovisual com o produto do levantamento histórico realizado pelos alunos ${ }^{12}$, com a participação de estudiosos da temática, e com o apoio da emissora de televisão da instituição, a UFN TV. Ainda foi realizada uma homenagem dos alunos aos ferroviários aposentados que auxiliaram no desenvolvimento dos trabalhos.

Figura 03 - O "Giro Histórico", atividade extensionista de finalização da disciplina de 2019.

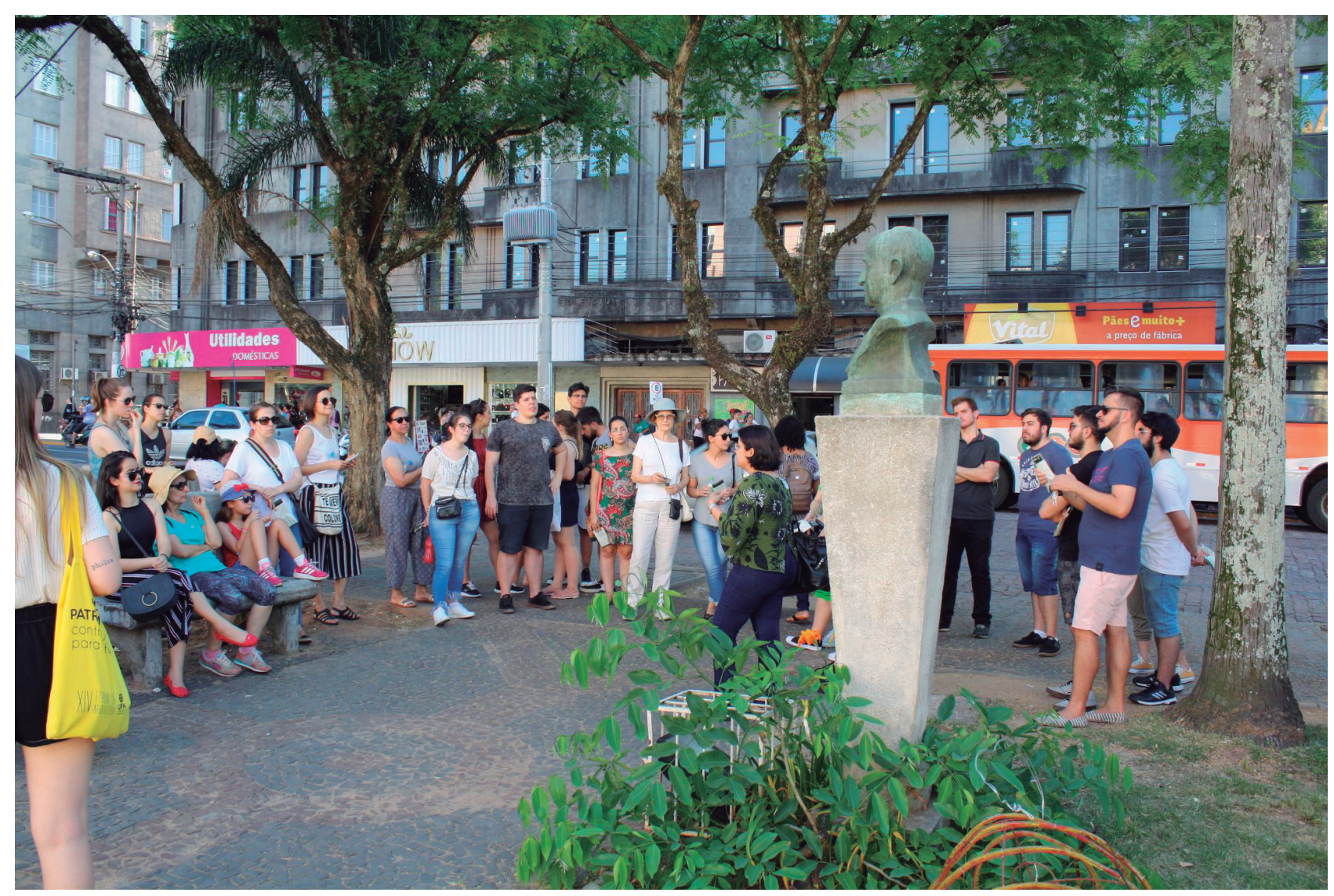

Fonte: Acervo dos autores, 2019.

11 Segundo Albano e Murta (2002), o projeto interpretativo é o processo de acrescentar valor à experiência do visitante, por meio do fornecimento de informações e representações que realcem a história e as características culturais e ambientais de um lugar. A interpretação do patrimônio ocorre através de guias de turismo, mapas ilustrados, roteiros de visita, panfletos, brochuras, cartões postais, placas, totens, painéis interativos, letreiros, miniaturas, hologramas, $Q R$ code, dentre tantos outros.

12 Audiovisual disponível em: https://www.youtube.com/watch?v=lcRnm5Pv3SY\&t=1s 
Figura 04 - Folder organizado pelo curso de Arquitetura e Urbanismo em parceria com o Design, Jornalismo e Publicidade e Propaganda, para o "Giro Histórico", atividade extensionista de finalização da disciplina de 2019.

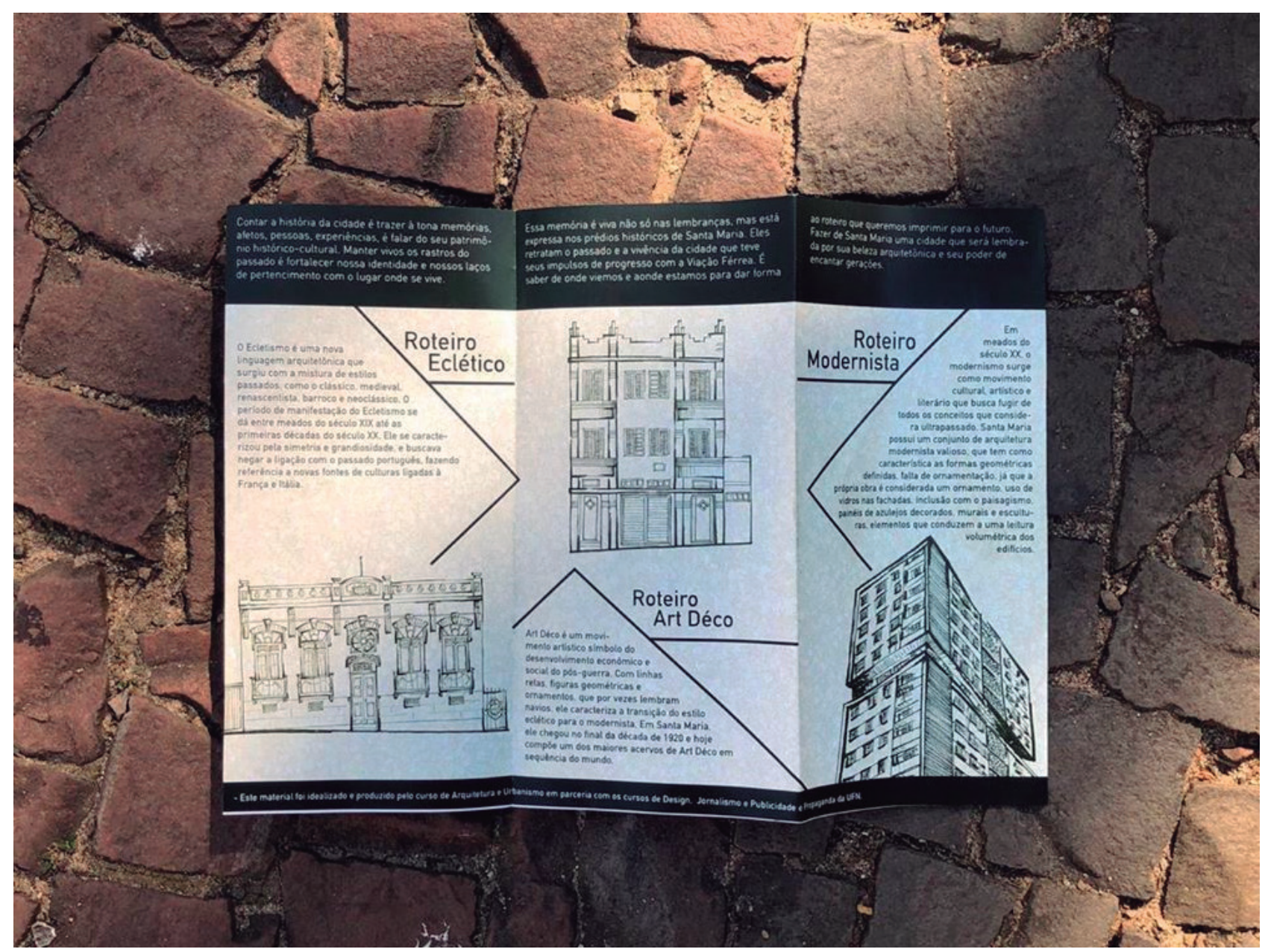

Fonte: Acervo dos autores, 2019.

\section{EDIÇÃO 2020: NOVAS FORMAS (REMOTAS) DE PROJETAR NOS ARMAZÉNS DA VIAÇÃO FÉRREA DO KM2}

Sem dúvidas, a reorganização das práticas do Ateliê para o segundo semestre de 2020 foi bastante contraditória e gerou alguns questionamentos sobre a edição de uma disciplina projetiva que tanto remete ao lugar sem o acesso pleno a este. Além disso, para esta é imprescindível a interação, comunicação e sincronia dos grupos de trabalho proporcionados pelo espaço físico dos Ateliês de Projeto. Pensar o modo remoto sobre algo que tanto depende da prática foi a premissa para a construção desta experiência. Para melhor compor as adaptações do programa, foi fundamental revisar as transformações que o Ateliê III vem passando nos últimos anos para melhorar as qualidades dos processos e resultados de trabalho.

O primeiro ponto a considerar é que esta disciplina está em constante transformação, principalmente quanto ao uso das tecnologias para a realização dos levantamentos e registros dos exemplares. A documentação do patrimônio é uma das áreas de conhecimento da arquitetura que mais se 
beneficia com o desenvolvimento das tecnologias. As ferramentas de levantamento como o 3D Laser Scanner, as imagens geradas por meio de Drones (Figura 05) e a fotogrametria são recursos cada vez mais acessíveis para análises e diagnósticos que visam maior precisão. As ferramentas da Fabricação digital também estão contribuindo para a documentação de exemplares e para o exercício de projeto.

A modelagem BIM, introduzida no curso de Arquitetura e Urbanismo da UFN desde 2011, cada vez mais presente neste âmbito, vem ganhando espaço para a documentação tridimensional e bidimensional de edificações de interesse patrimonial, devido a melhor integração e compatibilização dos dados.

Figura 05 - Imagem feita por drone para levantamento dos Armazéns do Km2.

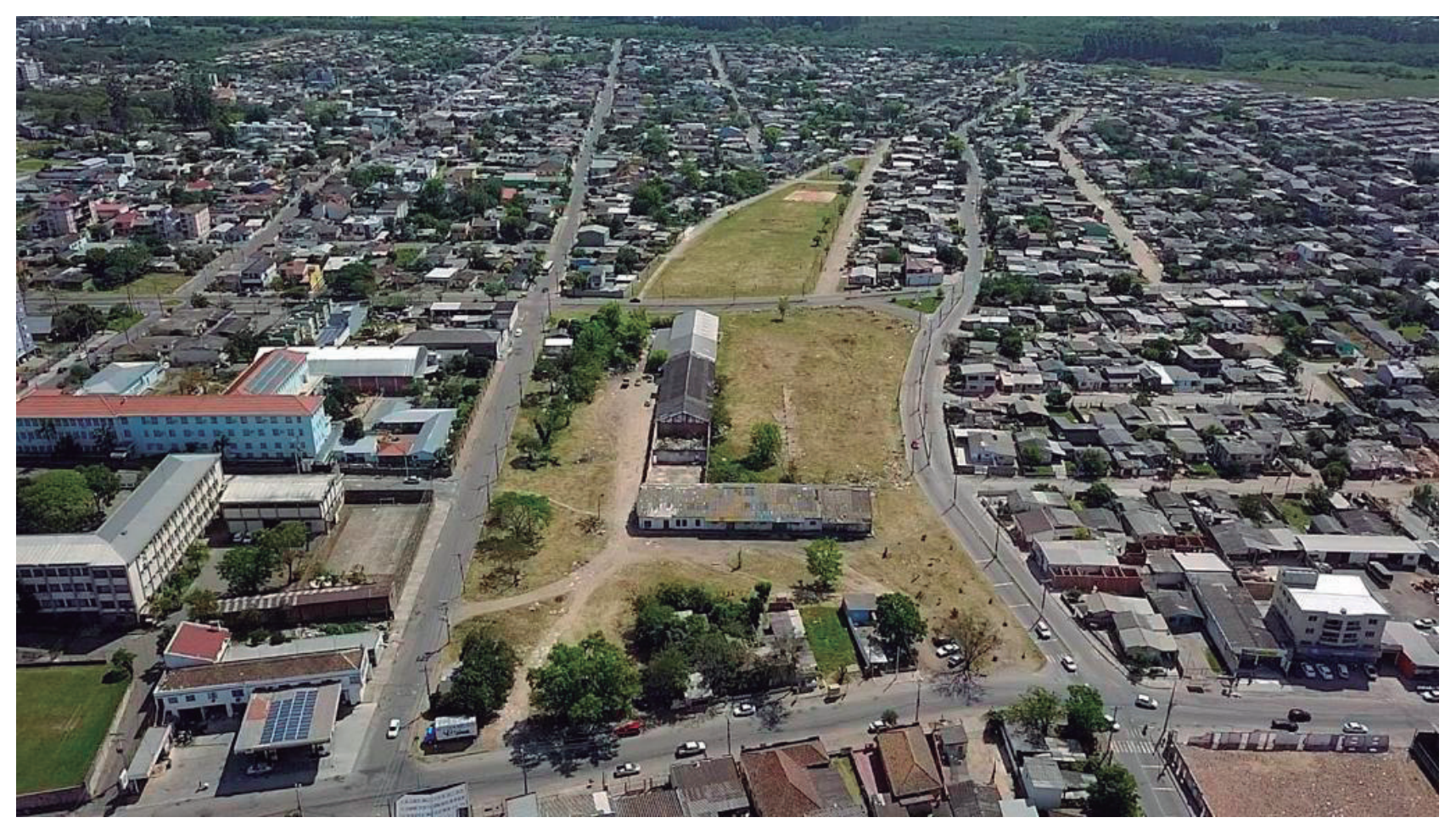

Fonte: Acervo dos autores, fotografia do acadêmico do ateliê III, Gustavo Menezes, 2020.

A aquisição e desenvolvimento de alguma destas ferramentas estão sendo introduzidas paulatinamente ao longo destes dez anos de investigação sobre o Patrimônio Ferroviário e vem contribuindo de forma positiva para a produtividade e qualidade dos resultados dos ateliês de projetos, pois permitem registros precisos e a abreviação no tempo de permanência para a coleta presencial de dados sobre o contexto em estudo. Estas contribuições foram essenciais para o exercício de intervenção na área dos antigos Armazéns da Viação Férrea do Km 2, situado no bairro Divina Providência em Santa Maria, RS.

O levantamento foi, sem dúvida, a parte da disciplina de maior desafio, pois a presencialidade é o momento de aproximação e entendimento das dimensões físicas, socioculturais e históricas do lugar. Estas análises foram separadas por grupos de trabalho e a distribuição dos temas foram conduzidas de acordo com as distintas habilidades, possibilidades e limitações impostas pela situação vigente. 
A plataforma escolhida para a interação entre professores e alunos, foi a Zoom Meeting, e as reuniões e assessoramentos eram realizados de forma síncrona seguindo uma estrutura similar à do cronograma presencial. Esta plataforma, ao contrário das outras, permitiu desenhos e anotações sobre o material compartilhado, muitas vezes com auxílio de outras plataformas e aplicativos ${ }^{13}$.

Os estudos históricos foram desenvolvidos por meio de pesquisa bibliográfica e pela leitura do estado atual das imagens do entorno, a análise da arquitetura relata a passagem do tempo. A inacessibilidade às bibliotecas e arquivos devido a situação vigente, proporcionaram uma força tarefa de compartilhamento de informações a partir da disponibilidade de material do grande grupo e dos arquivos digitais. Já o estudo sobre os Condicionantes Legais seguiu a mesma metodologia de coleta de dados pelo fácil acesso às redes digitais que disponibilizam as informações de legislação e normativas necessárias para a ideação da intervenção.

O levantamento de dados das escalas urbanísticas, macro e meso, também tiveram uma metodologia similar à do modo presencial: estes estudos foram analisados por meio de fotografias aéreas em diferentes aproximações, conforme a definição das análises. As fontes de pesquisas podem variar conforme o semestre e área, mas sobre os dados da cidade de Santa Maria tem como fonte principal o material disponibilizado pelo IPLAN. Enquanto a escala macro mostra as relações entre o natural e o construído e identifica o patrimônio ferroviário no contexto urbano, a escala meso revela informações de densidade de ocupação, alturas, uso do solo e a presença de áreas verdes na área fixada para o estudo. Esta forma de trabalho depende da atualização dos mapas bases e dos demais dados cartográficos disponibilizados. Ainda, para a escala meso, a saída de campo é fundamental para complementar a atualização destes dados tão relevantes para a construção da paisagem urbana. A seguinte aproximação denominada como escala micro, revisa a dimensão paisagística e arquitetônica e necessita desta visita técnica.

Um dos propósitos da disciplina do Ateliê III, é a elaboração de um levantamento arquitetônico completo, que contemple todas as informações relevantes sobre o estado vigente da edificação. Para isto, todavia é indispensável o uso de métodos tradicionais de medições e a formação de um grupo de trabalho específico devido à grande demanda de informações para a construção de uma leitura técnica bidimensional e um modelo tridimensional apto para a análise e manuseio. Este levantamento apreende os distintos aspectos sobre o entorno imediato e as diversas formas de aproximação à escala arquitetônica. Na dimensão física, a topografia e amarrações da edificação ao terreno são registradas assim como as informações de perímetro, alturas, superfícies, estruturas e

$13 \mathrm{O}$ modelo de trabalho utilizado para o trabalho síncrono buscou seguir a composição dos grupos conforme o formato presencial: quatro componentes para o partido urbanístico, dois componentes para o paisagístico e individual para o partido arquitetônico. Os alunos tiveram a orientação dos professores por meio de assessoramentos remotos durante os horários fixados para o ateliê, por meio da plataforma Zoom Meeting. Além desta, as correções de projeto também tiveram o suporte da plataforma colaborativa Conceptboard, que se mostrou ideal para a comunicação entre professores e alunos e para a interação entre os grupos, pois permite a manipulação e sobreposição das informações nas imagens de construção do partido. Outras formas de interação que aconteceram neste formato, foi o compartilhamento do modelo tridimensional via plataforma Zoom Meeting para melhor compreensão nas orientações. 
materialidades. Este exercício também tem como desígnio registrar os ornamentos e detalhes técnicos tão importantes para o entendimento das técnicas construtivas da época.

Para a edição de 2020, foi necessária uma adaptação desta parte do levantamento devido a impossibilidade de acesso aos Armazéns por medidas de segurança relacionadas à crise sanitária. Foi proporcionado aos alunos da disciplina, um levantamento prévio com as medidas externas e internas gerais e sem informações mais detalhadas.

A saída de campo reunindo alunos e professores do Ateliê III aos Armazéns do Km 2 (Figura 06), foi realizada no dia 2 de setembro de 2020, seguindo as medidas de segurança sugeridas pelo protocolo institucional da Universidade Franciscana. Foi estabelecido um roteiro de reconhecimento à área de estudo e organizado em dois turnos distintos para maior segurança do grupo. A visita teve acesso somente aos espaços externos do conjunto: além da leitura do entorno, esta foi uma das poucas atividades presenciais de interação entre professores e alunos e, também, foi uma oportunidade para a complementação do levantamento arquitetônico, fornecido excepcionalmente nesta edição da disciplina.

Figura 06 - Imagens dos Armazéns da viação Férrea do Km2.
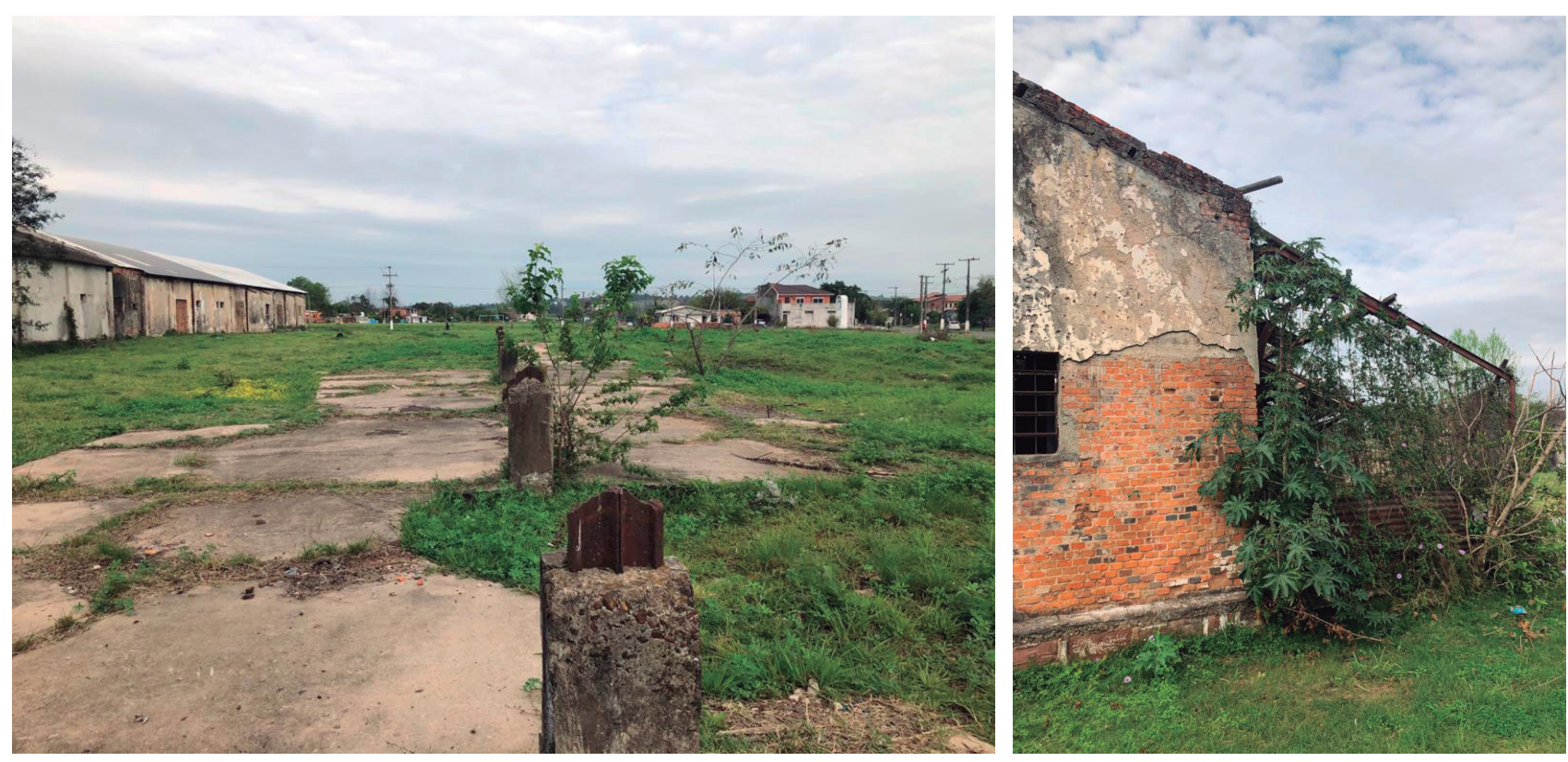

Fonte: Acervo dos autores, 2020.

A presencialidade neste roteiro também foi importante para o reconhecimento dos umbrais de acesso, das visuais do entorno, das relações das edificações vizinhas com o terreno, do estado de conservação das vias e passeios, da compreensão de como ocorrem os movimentos no bairro, entre outros fatores que somente é possível vivendo, vivenciando, o lugar.

Com a base consolidada para o estudo, o edital de partido Arquitetônico da disciplina buscou seguir o mesmo formato do modo presencial. O programa de necessidades proposto para a escala arquitetônica e paisagística foi de uma Biblioteca Pública e uma praça como extensão deste equipamento. 
Para a escala urbanística, o programa de necessidades foi composto conforme as distintas leituras dos grupos sobre as fragilidades e potencialidades da área em estudo.

Apesar das limitações em decorrência do distanciamento social, as respostas nas três distintas escalas foram bastante satisfatórias (Figura 07), embora não tenhamos aprofundado os detalhes construtivos de maneira mais realista, detalhes estes fundamentais para a elaboração deste tipo de projeto, conseguimos, por se tratar de uma edificação mais despojada de ornamentos, resultados volumétricos e de releituras formais mais inovadores.

Uma das principais considerações sobre esta edição, foi a prática de uma experiência bastante comum no exercício profissional: o trabalho de equipes multidisciplinares a distância, já consolidado no panorama da arquitetura e construção civil.

Figura 07 - Imagens dos projetos arquitetônicos e paisagísticos desenvolvidos pelos acadêmicos da disciplina para os Armazéns da viação Férrea do Km2.
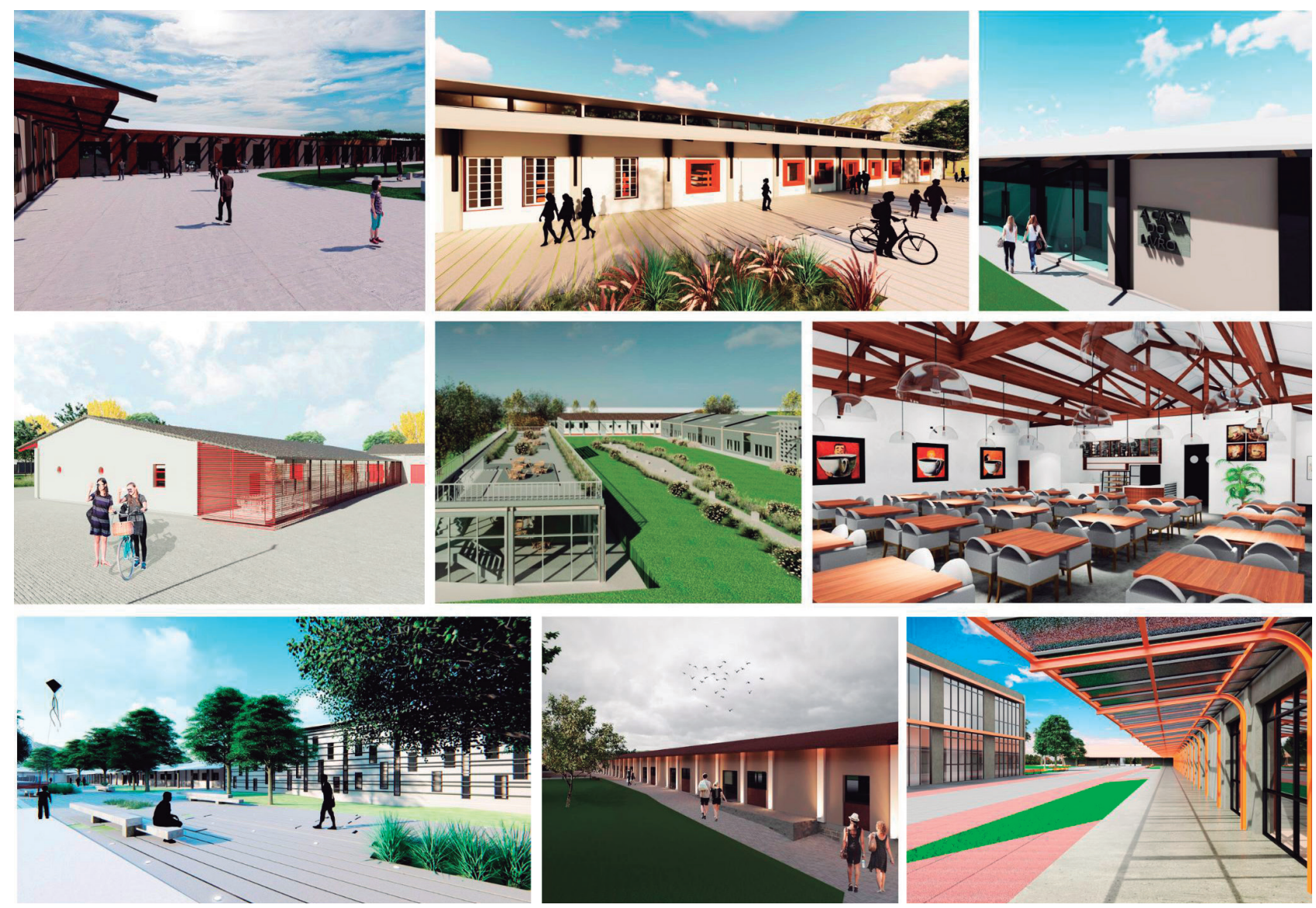

Fonte: Acervo dos autores, 2020.

As atividades extensionistas que foram elaboradas em relação ao levantamento consistiram na compilação e nas análises, porém, como anteriormente relatado, a atualização mais aproximada, mais detalhada, não foi possível. Já o produto foi expandido de modo virtual, além das adaptações mencionadas, a organização desta edição buscou alguns benefícios do modelo remoto com o intuito de compensar as deficiências em decorrência da não presencialidade. Sem dúvida, o modo remoto 
facilitou a conexão com escritórios, estúdios e coletivos de arquitetura, além de profissionais relacionados ao tema de diversas áreas, de projeção regional, nacional e internacional. Por meio de um evento denominado "Arq(in) Casa"14, organizado pelos laboratórios da Arquitetura e Urbanismo $\mathrm{UFN}^{15}$, foi possível aproximar outros contextos a este Ateliê de Projetos em que a presença e o lugar tanto significam (Figura 08).

Figura 08 - Fotomontagem dos materiais de divulgação do evento Arq (in) Casa com as videoconferências específicas para a temática do Ateliê III.
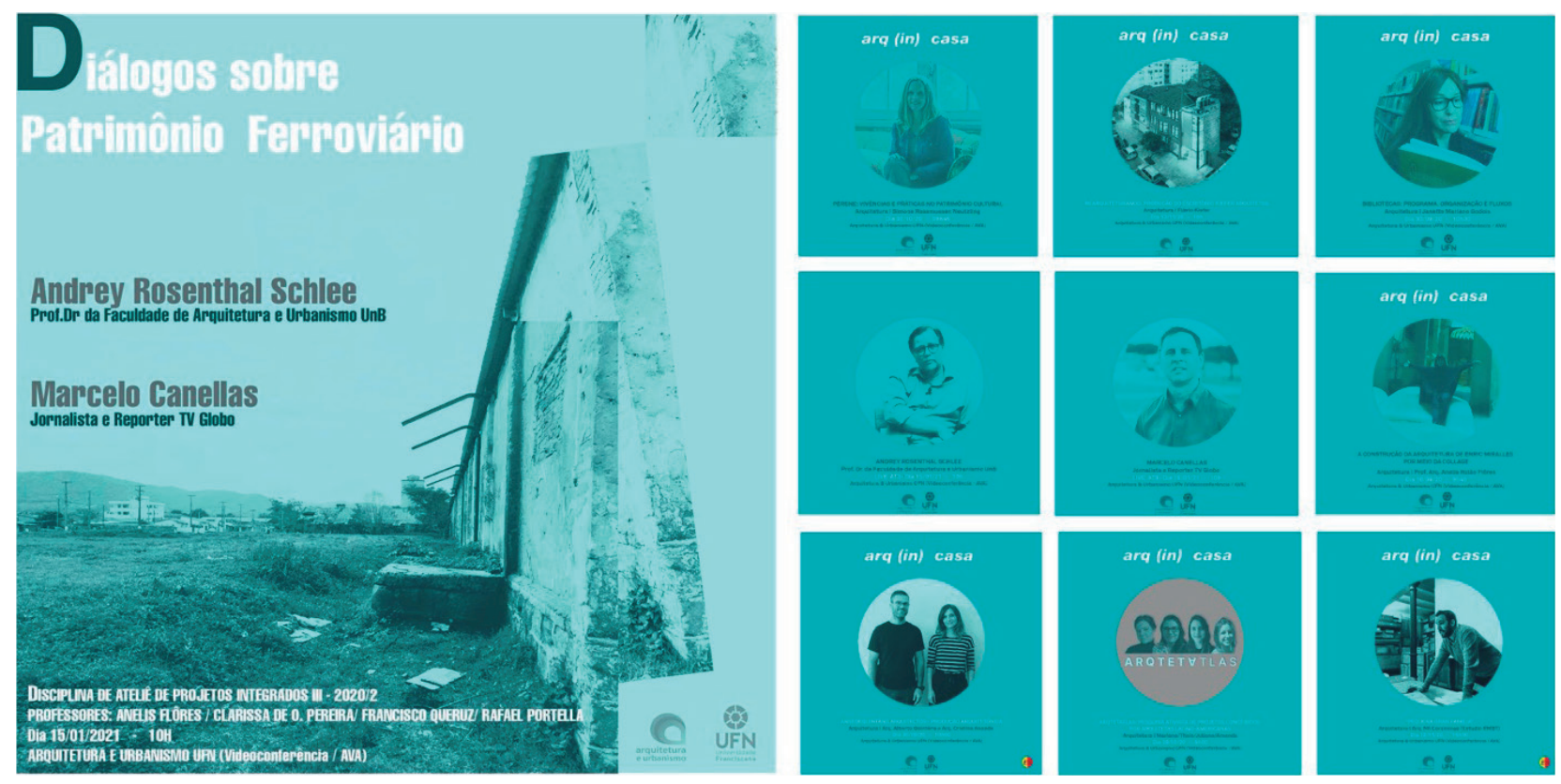

Fonte: Acervo dos autores, 2021.

Convém destacar a participação de representantes de escritórios de arquitetura nacionais como a Perene Cultural, de Pelotas, e Kiefer Arquitetos, de Porto Alegre, que contribuíram com as suas vivências e práticas profissionais sobre intervenções em preexistências. A arquiteta Simone Neutzling, sócia fundadora da Perene Cultural, compartilhou um modelo de trabalho voltado apenas para edificações de interesse patrimonial, mostrando todas as fases e componentes necessários para um levantamento cadastral padrão e a metodologia de desenvolvimento dos projetos realizados pelo seu estúdio. Além disso, trouxe a experiência prática de resgate de técnicas construtivas tradicionais para o entendimento e restauração das arquiteturas do passado. Em formato similar, o arquiteto Flávio Kiefer, autor de importantes projetos de intervenções em preexistências nacionais, expôs estudos de caso de sua autoria desenvolvidos no estúdio de arquitetura Kiefer Arquitetos, esclarecendo por meio da sua prática, termos bastante importantes sobre os distintos níveis de intervenção em edifícios preexistentes.

$14 \mathrm{O}$ evento Arq (in) Casa promoveu vinte e seis (26) videoconferências durante o ano de 2020, sendo oito (8) destas com temas direcionados para o Ateliê III, para o complemento desta área de conhecimento.

15 Atualmente os laboratórios envolvidos no "Arq(in) Casa” do curso de Arquitetura e Urbanismo, são os seguintes: Ambiente de Pesquisa e Documentação (APD), Ambiente de Prática Profissional (APP) e Laboratório de Conforto. 
Outros profissionais de abrangência internacional que contribuíram com o tema foram os arquitetos Alberto Quintans, do Estúdio Ansede Quintans de Santiago de Compostela (ES) e Nil Corominas, representando o estúdio EMBT de Barcelona (ES). Quintans apresentou a experiência prática de uma escala de intervenção arquitetônica bastante comum do cenário espanhol. A sua prática tem como base uma pesquisa histórica e cultural aprofundada para a avaliação dos níveis de intervenção. A sua exposição, mostrou o trabalho de integração entre distintos profissionais e a valorização que o país Ibérico, todavia preserva com práticas precedentes quase artesanais. Já o Arquiteto Nil Corominas trouxe os aspectos conceituais e experimentais realizados pelo estúdio EMBT, de projeção internacional, dentro de um modo de projetar em que mostra a originalidade e o enlace poético entre o velho e o novo, contados em obras representativas como a intervenção no Mercat de Santa Caterina de Barcelona.

Assuntos complementares foram tratados como o funcionamento e operação das bibliotecas, fundamental para o entendimento do programa de necessidades, na videoconferência ministrada pela profissional da área da biblioteconomia Janette Godois da UFN, e o panorama das mulheres na arquitetura, exposto pelo coletivo Arquitetatlas de São Paulo. A apresentação da Tese de doutorado da professora Anelis Rolão Flôres (UFN), também contribuiu com os aspectos conceituais para os processos de projeto desde a perspectiva da Collage na arquitetura.

O encerramento da disciplina teve como objetivo um diálogo sobre o Patrimônio Ferroviário com maior alcance comparado aos demais eventos. A exposição e debate em formato de Live, teve como convidados, o professor Dr. Andrey Rosenthal Schlee da FAU-UnB e o jornalista e repórter da TV Globo, Marcelo Canellas, que abordaram não apenas o contexto da cidade ferroviária mas, também, reflexões gerais sobre os valores históricos, econômicos, ambientais que envolvem a memória através da arquitetura desde pontos de vistas complementares.

\section{RESULTADOS E DISCUSSÕES}

A partir da participação no projeto de extensão institucional Centro Histórico de Santa Maria e da inclusão da disciplina no currículo do curso de Arquitetura e Urbanismo como extensionista, as edificações remanescentes do patrimônio ferroviário local foram incluídas no resgate realizado pelos acadêmicos, possibilitando a elaboração de material inédito e complementar, fundamental para o encaminhamento de ações que visam a preservação em seus diversos níveis de atuação.

No ano de 2019, o levantamento cadastral atualizado da Estação Férrea de Santa Maria possibilitou ao poder público agilidade na abertura de edital público para o projeto de revitalização do edifício. O material prévio, do poder público municipal, possuía defasagem de sete anos, período que 
para este tipo de registro que fornece dados de edificação histórica em situação de desuso e ausência de manutenção acaba inviabilizando sua utilização.

Também em 2019, o diagnóstico urbanístico realizado serviu para registro das modificações ocorridas no entorno da edificação, material essencial para a previsão de novos projetos e poderá auxiliar como consulta a novas diretrizes urbanísticas, macro, meso e micro, assim como balizar a implantação, e aprovação, de novos projetos privados na área.

O produto final de 2019, chamado Giro histórico, considerado uma ação extensionista ampla, englobando a sociedade como um todo, além de possibilitar a aproximação de alunos, professores e instituição de ensino com a comunidade e o poder público, também permitiu a elaboração preliminar de um projeto interpretativo na Avenida Rio Branco que atualmente está sendo desenvolvido em um projeto de extensão próprio, originando o grupo "Mapeando Memórias".

Em 2020, no estudo dos Armazéns do Km2, a dificuldade de interação e de uma maior discussão impostas, a princípio, pelo distanciamento social, foram superadas por um novo olhar sobre a extensão. O levantamento cadastral não foi atualizado, mas o diagnóstico urbanístico a partir de base de dados e as pesquisas em material de acervos digitais possibilitou a organização de um material conciso. Mesmo com o distanciamento, os acadêmicos produziram um cenário com memórias orais, registros de evolução urbana e todo o material gráfico necessário para a elaboração do projeto.

O evento Arq (in) Casa, com temas voltados para o desenvolvimento de projetos de patrimônio e da sua consequente preservação, foi potencializado pelo modo virtual, e como foi aberto para convidados externos, na sua maioria de grupos ligados à preservação dos remanescentes locais, possibilitou uma maior abrangência de discussões. Esses tipos de conferências seriam inviabilizados por questões econômicas se fossem presenciais, demonstrando um novo caminho de trocas de experiências profissionais que na nossa análise será irreversível.

O produto final da disciplina, incluído dentro deste evento, reuniu na conferência virtual de encerramento, denominada, "Diálogos sobre Patrimônio Ferroviário" uma discussão mais aprofundada sobre os caminhos da preservação não apenas locais, como principalmente nacionais, em um momento de abandono por parte do poder público federal e de desconhecimento da sociedade sobre sua importância social e potencialidades de desenvolvimento.

Finalmente, convém ressaltar que o "Giro Histórico" foi um dos vencedores da segunda edição do Prêmio CAU-RS, em 2020, consolidando a atuação da disciplina sobre a temática da preservação do Patrimônio Ferroviário da região central do estado. O prêmio concedido, na categoria da iniciativa privada, à reitora Iraní Rupolo demonstra a importância de iniciativas que contribuem para a disseminação de conhecimentos da área patrimonial para a sociedade. 


\section{CONSIDERAÇÕES FINAIS}

Sem o lugar (e isto bem sabe os loucos, os perdidos no deserto, ou no mar, ou na neve, ou simplesmente os emigrantes), se rompe a razão entre a história e o sujeito; o lugar permite ao sujeito navegar pela história e permite a história situar o sujeito. Juntos (o sujeito, a história e o lugar), são capazes de multiplicar-se de desenvolver-se. Separados, perecem forçosamente de inanição (MUNTAÑOLA, 2000, p. 17) (Tradução nossa).

Segundo Muntañola, a razão do lugar começa na consciência de que a única ponte entre este e a história, é o sujeito com sua presença. No mesmo ensaio, ele também observa que atualmente a busca destas razões deixaram de ser prioridade para dar ênfase a uma visão mais reducionista sobre o significado do lugar na arquitetura, como o ócio, a proteção e a sobrevivência.

O Ateliê III, talvez seja a disciplina que melhor representa estes conceitos, pois convida a intervir em estruturas consolidadas onde a história e a cultura se cruzam em narrativas contadas pela própria arquitetura. $\mathrm{O}$ enlace ético (e poético), entre o velho e o novo resultam em discussões aprazíveis que acontecem não apenas no âmbito da sala de aula, mas em aproximar e revisitar as três escalas do espaço sócio físico, definidas para o estudo.

Atualmente, o patrimônio cultural, seja ele material ou imaterial, vem sendo ameaçado não apenas pela negligência das políticas públicas e redução de recursos, como ainda pelo total desconhecimento do seu verdadeiro papel na construção da autoestima da sociedade. O patrimônio material carece, além do seu cuidado e valorização, de adaptações à vida contemporânea, que possibilitem a sua utilização evitando a museificação. As edificações remanescentes devem ser consideradas em conjunto com o seu entorno para configurarem um complexo capaz de impulsionar o turismo e, ainda, o uso efetivo de seus usuários. Para tanto, o principal objetivo da preservação do patrimônio "é educar, ajudar a compreender a complexidade de nossas cidades, dar referência do melhor de nossa produção (...) O passado só nos interessa enquanto vivo, enquanto sirva de alimento" (FERRAZ, 2011, p. 159).

Essa condição de precariedade e urgência foi agravada em 2018, em Santa Maria e região, pela desproteção da zona 2 e ainda mais pela situação econômica imposta pela COVID-19, levando muitas edificações de interesse patrimonial à desconfiguração, decadência e inclusive demolição. Com isso, o discurso preservacionista precisou ser destacado ainda mais na formação dos futuros arquitetos e as estratégias de promoção avaliadas e potencializadas. E verificou-se que a importância do patrimônio e da memória na construção da sociedade precisam fazer parte de ações extensionistas que venham a expandir e consolidar a educação patrimonial, pois apenas os recursos de legislação e controle do estado não tem se mostrado eficientes para a salvaguarda.

Dentro deste contexto, a disciplina, ainda, possui caráter extensionista que antecede a curricularização da extensão, promovendo desde sua primeira edição ações de promoção do patrimônio arquitetônico remanescente do interior do estado. Em 2019, ao integrar o projeto de extensão 
institucional, além do produto do levantamento e resgate das memórias realizados anteriormente, o grupo organizou o "Giro Histórico" como uma ação macro de promoção da preservação da área central de Santa Maria. Já em 2020, a conferência virtual permitiu uma abrangência ainda maior possibilitando os diálogos sobre a preservação do patrimônio ferroviário nacional e local, e trouxe reflexões sobre os entraves nas diversas esferas.

Os acadêmicos do Ateliê III vem desenvolvendo projetos que reinterpretam a história e propõe novos usos para estas edificações, oportunizando ideias que potencializam as edificações e seus entornos, como por exemplo, centros comunitários, complexos culturais, bibliotecas, pousadas, vinícolas, projetos interpretativos, praças, etc. Ideias essas que são compartilhadas com a sociedade e conseguem extrapolar os limites acadêmicos e implementar a conscientização da preservação.

Afinal, é importante estabelecer a educação patrimonial como uma ferramenta que possibilita o desenvolvimento da cidadania e da transformação social pelo sentimento de pertencimento. Ela desempenha a função de condutora na construção do conhecimento, capaz de permitir um papel ativo dos cidadãos, instigando a capacidade de leitura, interpretação e questionamento dos espaços patrimoniais de memória, podendo ultrapassar o patrimônio e alcançar esferas sociais e políticas. Pode assim influenciar na consolidação de um cidadão consciente e participativo na construção do patrimônio, e numa esfera mais ampla, na construção de nossa cidade e sociedade.

\section{REFERÊNCIAS}

ALBANO, C.; MURTA, S. (Orgs). Interpretação do patrimônio: um exercício do olhar. Belo Horizonte: UFMG; Território Brasilis, 2002.

ASSMANN, Aleida. Espaços da recordação: formas e transformações da memória cultural. Campinas, SP: Unicamp, 2011.

BELÉM, João. História do município de Santa Maria 1797-1933. 3. ed. Santa Maria, RS: Ed. da UFSM, 2000. 309 p.

BELTRÃO, Romeu. Cronologia Histórica de Santa Maria e do extinto município de São Martinho. 2. ed. Santa Maria, RS. Editora Palotti, 1979.

DIAS, José Roberto de Souza. Caminhos de Ferro do Rio Grande do Sul: uma contribuição ao estudo da formação histórica do sistema de transportes ferroviários no Brasil meridional. São Paulo: Rios, 1986. 
FERRAZ, Marcelo Carvalho. Arquitetura conversável. Rio de Janeiro, RJ: Beco do Azougue, 2011.

FORTES, Ariosto Borges. Viação Férrea no RS - Suas estações e paradas. Porto Alegre: 1962.

KÜHL, Beatriz Mugayar. Preservação do Patrimônio Arquitetônico da Industrialização: Problemas Teóricos de Restauro. Cotia, SP: Ateliê Editorial, 2008.

MELLO, Luiz Fernando da Silva. O pensamento utópico e a produção do espaço social: a cooperativa de consumo dos empregados da viação férrea do Rio Grande do Sul. 2010. Tese (Doutorado pelo Programa de Pós-Graduação em Planejamento Urbano e Regional) - Universidade Federal do Rio Grande do Sul - Porto Alegre, 2010.

MUNTAÑOLA T., Josep. Topogénesis: Fundamento de una nueva arquitectura. Barcelona: Ediciones UPC. 2000.

QUEIROZ, Maria Isaura Pereira de. Relatos orais: do “ indizível” ao "dizível”. In: Experimentos com história de vida: Itália- Brasil. São Paulo: Vértice, 1988. 